\title{
氧杂环丁烷的扩环反应
}

\author{
袁文豪许家喜* \\ (北京化工大学化学学院有机化学系 化工资源有效利用国家重点实验室 北京 100029)
}

\begin{abstract}
摘要 氧杂环丁烷是一类重要的小杂环化合物, 也是重要有机合成中间体, 在有机化学、药物化学和高分子化学中都 有广泛的应用. 作为具有较大环张力的小杂环化合物, 氧杂环丁烷类化合物除可以发生开环反应外, 也很容易发生扩 环反应, 构建含氧普通环到大环化合物. 主要总结了氧杂环丁烷的扩环反应, 包括重氮化合物作为卡宾前体与氧杂环 丁烷的扩环反应、金属催化的分子间环加成和邻基参与的分子内环加成反应及亲核扩环反应等. 分析了一些扩环反应 的机理, 并对扩环反应未来的发展提出了新的展望.
\end{abstract}

关键词 氧杂环丁烷; 扩环; 卡宾; 环加成; 亲核反应

\section{Ring Expansions of Oxetanes}

\author{
Yuan, Wenhao Xu, Jiaxi* \\ (State Key Laboratory of Chemical Resource Engineering, Department of Organic Chemistry, College of Chemistry, \\ Beijing University of Chemical Technology, Beijing 100029)
}

\begin{abstract}
Oxetanes are a class of important small heterocycles and intermediates in organic synthesis and have been widely applied in organic, pharmaceutical and polymer chemistries. As small heterocycles with a large ring tension, oxetanes not only prefer ring-opening reactions, but also favor ring expansions, to construct oxygen-containing common to large heterocyclic compounds. The ring expansion reactions of oxetanes, including the ring expansions with diazo compounds as carbene precursors, the metal catalyzed intermolecular cycloadditions and the intramolecular cycloadditions involving neighboring group participation, the nucleophilic ring expansion and so on are reviewed. Some reaction mechanisms of ring expansion reactions are analyzed, and new prospects for the future development of the ring expansion reactions are put forward.

Keywords oxetane; ring expansion; carbene; cycloaddition; nucleophilic reaction
\end{abstract}

氧杂环丁烷不仅是许多天然生物活性分子的重要 结构单元, 也是一类重要的人工合成的含氧小杂环化合 物, 因其特殊的空间结构可以作为药物的药效基团而引 起了广泛的关注 ${ }^{[1]}$. 同时, 也被广泛应用于高分子材料 化学领域 ${ }^{[2]}$. 与三元杂环化合物类似 ${ }^{[3-10]}$, 四元杂环也 属于小杂环化合物, 具有较大的环张力, 易发生开 环 $^{[11-12]}$ 和扩环反应 ${ }^{[13-14]}$. 在过去的几十年中, 氧杂环丁 烷的开环和官能团化研究已取得了许多进展 ${ }^{[15]}$, 并且 利用氧杂环丁烷作为合成中间体扩环构建杂环化合物 的新策略不断涌现 ${ }^{[16]}$. 本文主要综述了氧杂环丁烷通 过扩环反应合成更大的含氧杂环化合物方面的研究工 作.

\section{1 与重氮类化合物的扩环}

\section{1 氧杂环丁烷与重氮化合物的扩环反应}

最早报道的氧杂环丁烷的扩环反应是氧杂环丁烷 在 $\mathrm{Cu} 、 \mathrm{Rh}$ 等金属催化下，与重氮化合物发生的扩环反 应. 从机理上讲, 重氮类化合物与 $\mathrm{Cu} 、 \mathrm{Rh}$ 等金属反应 会生成金属卡宾, 金属卡宾具有亲电性, 会与氧杂环丁 烷中的氧原子发生亲电反应形成碳氧叶立德, 再发生 Stevens 重排等反应, 得到扩环产物. 最近, 也有在光照 条件下, 重氮类化合物直接生成卡宾与氧杂环丁烷发生 扩环反应的报道.

1966 年, Noyori 等 ${ }^{[17-18]}$ 最早报道了使用重氮乙酸甲

\footnotetext{
* Corresponding author. E-mail: jxxu@mail.buct.edu.cn Received August 25, 2020; revised September 22, 2020; published online October 13, 2020. Project supported by the National Natural Science Foundation of China (No. 21772010). 国家自然科学基金(No. 21772010)资助项目.
} 
酯 2 在手性 $\mathrm{Cu}(\mathrm{II})$ 催化剂 3 催化下不对称地插入 2-苯基 氧杂环丁烷(1a)中, 形成 3-苯基四氢呋喃-2-甲酸甲酯 4 (Scheme 1). 产物产率达到 85\%, 非对映选择性 cis : trans $=1: 2$. 重氮化合物在铜催化作用下, 生成铜卡宾, 其中卡宾部分作为第五配体与金属结合, 该卡宾具有良 好的亲电性, 可以实现氧杂环丁烷的扩环.

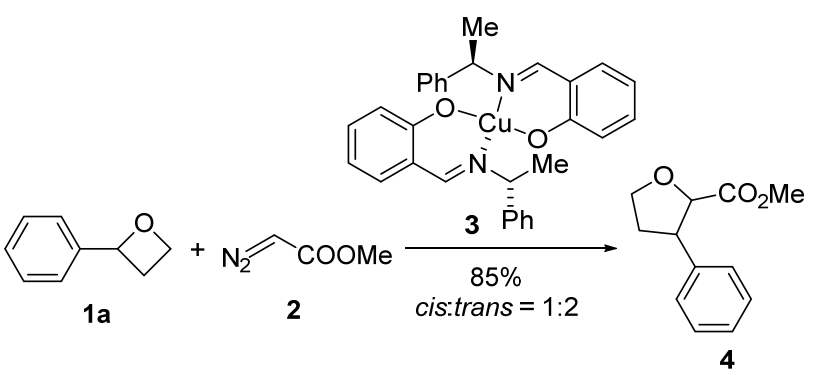

图式 12 -苯基氧杂环丁烷和重氮乙酸甲酯的反应 Scheme 1 Reaction of 2-phenyloxetane with methyl diazoacetate

1994 年, Katsuki 等 ${ }^{[19-24]}$ 改进了这个反应, 用重氮乙 酸叔丁酯在 $1 \mathrm{~mol} \%$ 的 CuOTf 和手性联吡啶配体 $\mathbf{5}$ 的催 化下与外消旋的 2-苯基氧杂环丁烷(1a)反应(Scheme 2), 以 $36 \%$ 的产率得到了反式-和顺式-四氢呋喃产物 6 和 7 的混合物, 并回收了 $30 \%$ 的氧杂环丁烷原料 1a, 产物的 非对映体比例 trans : cis = 59:41, 反式产物 ee 值为 $75 \%$, 顺式产物 $e e$ 值为 $81 \%$. 使用大位阻的重氮乙酸叔 丁酯, 并未提高非对映选择性. 2-苯乙炔基氧杂环丁烷 (1b) 可以在该条件下以 $88 \%$ 的产率转化为 $c i s:$ trans $=$ $1: 1$ 的混合四氢呋喃衍生物 8 . 随后, 将该反应应用于 trans- $(+)$-whisky lactone (9)的全合成中 ${ }^{[20]}$.

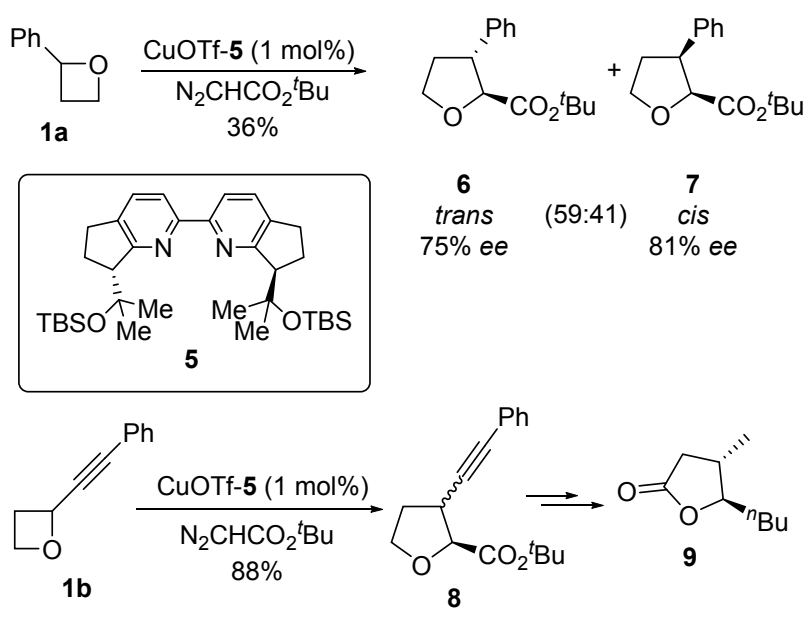

图式 2 CuOTf 和手性联吡啶催化的氧杂环丁烷的扩环反应 Scheme 2 Ring expansion of oxetanes catalyzed by CuOTf and chiral bipyridyl

为了提升氧杂环丁烷和重氮化合物反应的立体选 择性, 2001 年, $\mathrm{Fu}$ 等 $^{[25]}$ 报道了 $1 \mathrm{~mol} \% \mathrm{CuOTf}$ 和双(氮杂
二茂铁)络合物催化的 2-取代氧杂环丁烷的扩环反应 (Scheme 3). 对映体纯的 2-取代氧杂环丁烷 1 和重氮乙 酸酯在 $1 \mathrm{~mol} \% \mathrm{CuOTf}$ 和双(氮杂二茂铁)络合物 11 催化 下进行常温反应，可以以较高收率以及高非对映和对映 选择性获得相应的扩环产物 12 和 13 . 铜和双(氮杂二茂 铁)配合物的结构决定了产物的非对映选择性, 使用空 间位阻大的重氮乙酸酯 10 可以获得最高的非对映选择 性. 对于 2 -苯基氧杂环丁烷(1a), 使用 $(R, R)$-双(氮杂二 茂铁)配体产物顺式和反式比例达到 $5: 95$, 反式产物的 $e e$ 值可以高达到 $98 \%$; 而使用 $(S, S)$-双(氮杂二茂铁)配体 产物顺式和反式比例为 $84: 16$, 顺式产物的 $e e$ 值可以 达到 95\%. 配体构型的改变可以调整产物的非对映选择 性. 当 2-芳基氧杂环丁烷 1 的苯环上带有给电子取代基 时，会导致产物的非对映选择性下降.

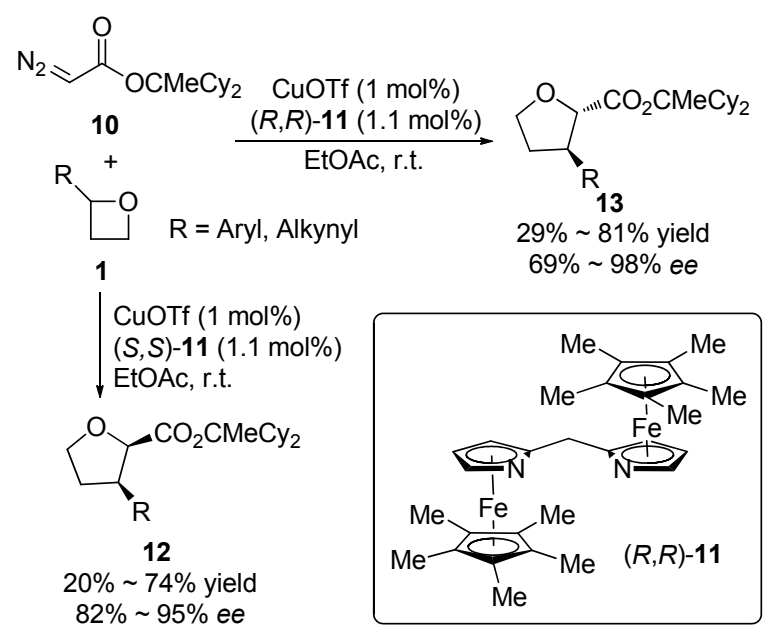

图式 $3 \mathrm{CuOTf}$ 和双(氮杂二茂铁)催化的氧杂环丁烷的扩环反 应

Scheme 3 Ring expansion of oxetanes catalyzed by CuOTf and bisazaferrocene

2012 年, Njardarson 等 ${ }^{[26]}$ 报道了 2-乙烯基氧杂环丁 烷(1c)在三氟乙酰丙酮(thfacac)铜(II)催化下, 与重氮乙 酸乙酯 14 或者重氮丙二酸二甲酯 15 在二氯甲烷回流条 件下反应, 生成四氢呋喃衍生物 16 和副产物 2,3,6,7-四 氢噁庚英衍生物 17 (Scheme 4). 两个反应产率分别为 $72 \%$ 和 $86 \%$. 此方法化学选择性不够理想, 但还适用于 乙烯基氧杂环丙烷 18 和乙烯基四氢呋喃 19 的扩环反应.

近年来, 可见光催化的有机化学反应成为有机合成 的研究热点, 2019 年, Koenigs 等 ${ }^{[27]}$ 报道了蓝光照射下的 重氮化合物和氧杂环丁烷的扩环反应(Scheme 5). 在蓝 色 LED (3 W, $470 \mathrm{~nm}$ ) 照射下, $2 \mathrm{~h}$ 内, 向 3,3-二取代氧杂 环丁烷 20 的氯仿溶液中通过注射洜加入芳基重氮酯 $\mathbf{2 1}$, 然后再搅拌 $1 \mathrm{~h}$, 以 $61 \% \sim 93 \%$ 的产率得到四氢呋喃衍 生物 22. 为了验证光照的必要性, 尝试了无光照 $\mathrm{Rh}_{2}(\mathrm{OAc})_{4}$ 催化的反应条件, 发现得到的扩环产物的产 


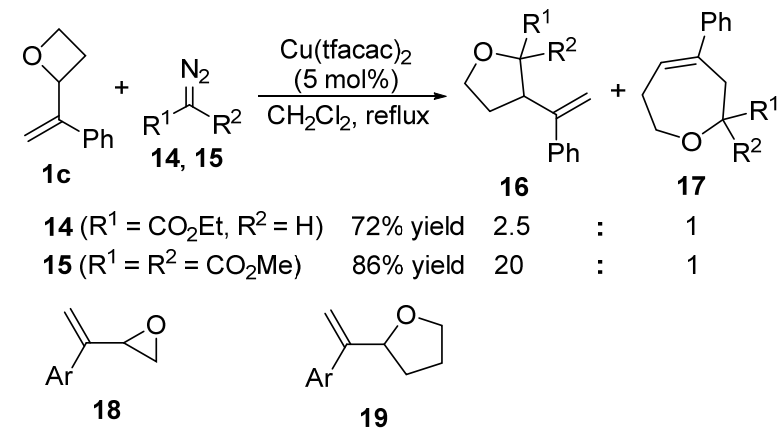

图式 $4 \mathrm{Cu}(\mathrm{tfacac})_{2}$ 催化的氧杂环丁烷的扩环反应 Scheme 4 Ring expansion of oxetane catalyzed by $\mathrm{Cu}(\mathrm{tfacac})_{2}$ 率明显降低. 对于非对称的氧杂环丁烷, 反应会生成比 例为 $1: 1$ 的两种非对映异构体混合的扩环产物. 蓝光 照射下 2-苯基氧杂环丁烷(1a)与芳基重氮酯 $\mathbf{2 1 a}$ 的光催 化扩环反应, 以 $64 \% \sim 84 \%$ 的产率得到了 $2,2,3$-三取代 四氢呋喃衍生物 23 , 其中顺式产物为主要产物, 产物 d.r. $>20 ： 1$. 在使用 $(-)$-薄荷醇衍生的重氮酯 24 与 3,3二甲基氧杂环丁烷 $20 \mathrm{a}$ 反应时，以 $62 \%$ 的产率生成四氢 呋喃衍生物 25, 产物 d.r. $>20 ： 1$.

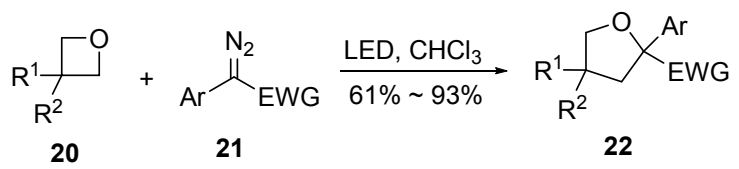

$\mathrm{R}^{1}, \mathrm{R}^{2}=$ Alkyl, $\mathrm{H}$

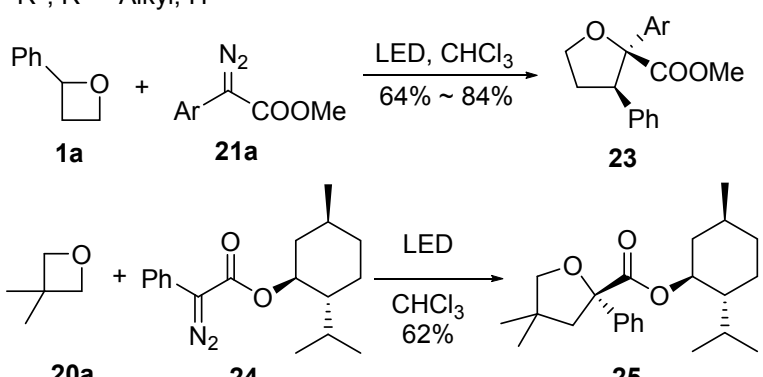

图式 5 光催化的氧杂环丁烷的扩环反应

Scheme 5 Photocatalytic ring expansion reaction of oxetanes

依据密度泛函理论(DFT)计算提出的光引发的卡宾 转移反应机理如下(Scheme 6): 在蓝光照射下, 芳基重 氮酯先生成卡宾 $\mathbf{2 6}$, 再和氧杂环丁烷反应经过渡态 $\mathbf{2 7}$, 随后转化为内酯中间体 $\mathbf{2 8}$, 接着 $\mathrm{C}-\mathrm{O}$ 键均裂经过渡态 29, 形成为双自由基中间体 30,30 经历过渡态 31 发生分 子内自由基-自由基偶联, 最终生成四氢呋喃衍生物 22 a.

2017 年, Lacour 等 ${ }^{[28]}$ 对重氮化合物和氧杂环丁烷的 反应做了进一步研究, 使用 $\left[\mathrm{CpRu}\left(\mathrm{CH}_{3} \mathrm{CN}\right)_{3}\right]\left[\mathrm{BAr}_{\mathrm{F}}\right]($ 简 写为 $[\mathrm{Ru}]$ )和 1,10-菲咯啉(phen)的催化组合, 氧杂环丁烷 和 $\alpha$-重氮- $\beta$-酮酸酯, 在二氯甲烷中于 $30{ }^{\circ} \mathrm{C}$ 反应 $16 \mathrm{~h}$,

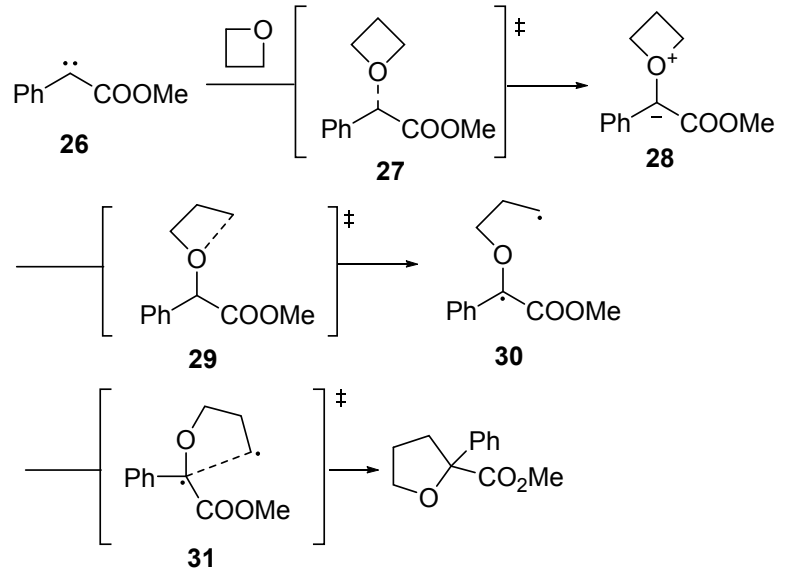

图式 6 光催化扩环反应的反应机理

Scheme 6 Reaction mechanism of the photocatalytic ring expansion of oxetane

可以生成 1,4-二氧杂环庚烯(Scheme 7). 该反应具有良 好的底物适用性，2-萗基氧杂环丁烷(1d)和多种不同取 代的 $\alpha$-重氮- $\beta$-酮酸酯 32 进行反应，以 $22 \% \sim 40 \%$ 的产 率得到相应的 1,4-二氧杂环庚-2-烯 33. 接着使用多种不 同取代的 2-芳基氧杂环丁烷 1 和 $\alpha$-重氮- $\beta$-酮酸酯 34 进 行反应，以 $32 \% \sim 61 \%$ 的产率得到相应的 1,4 -二氧杂环 庚-2-烯 35. 该反应条件温和, 但反应时间较长, 且反应 产率普遍偏低.
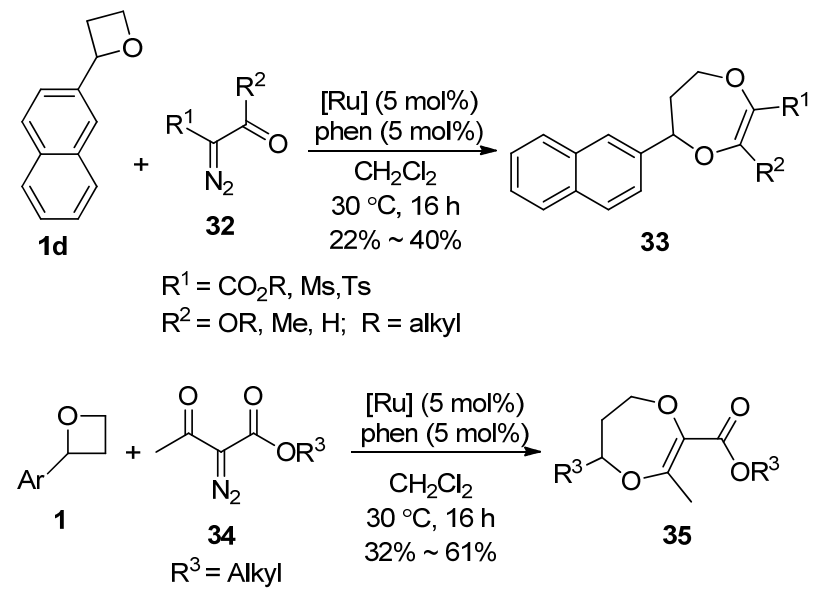

图式 $7 \mathrm{Ru}$ 催化的重氮酮酯与氧杂环丁烷的反应 Scheme 7 Ru-catalyzed reaction of diazoketoesters with oxetanes

该反应体系的机理如下 (Scheme 8): 首先, [CpRu$\left.\left(\mathrm{CH}_{3} \mathrm{CN}\right)_{3}\right]\left[\mathrm{BAr} \mathrm{F}_{\mathrm{F}}\right]$ 与 1,10 -菲咯啉反应生成 $[\mathrm{CpRu}(\mathrm{phen})-$ $\left.\left(\mathrm{CH}_{3} \mathrm{CN}\right)\right]\left[\mathrm{BAr}_{\mathrm{F}}\right]$ 复合物 36; 然后, 乙腈配体解离, 形成 具有催化活性的 16 电子物质 37 ; 在重氮化合物 32 亲核 进攻 37 并释放氮气后，生成金属卡宾 38.38 是具有亲电 性的费歇尔卡宾; 具有路易斯碱性的氧杂环丁烷 1 亲核 进攻金属卡宾 38 生成氧鎓叶立德中间体 39; 由于环张 力和芳香环的亲电活化, $\mathrm{C}-\mathrm{O}$ 键会裂解形成稳定的碳 
正离子中间体 40; 然后羰基捕获碳正离子, 会快速地生 成分子内七元环中间体 41; 之后, 释放催化剂 37 和 1,4二氧杂环庚-2-烯 33, 完成催化循环. 仔细分析发现, 反 应会生成比例为 $5 \% \sim 10 \%$ 的四氢呋喃衍生物, 但产率 远远低于 1,4-二氧杂环庚-2-烯. 应用 Baldwin 闭环规则 可以解释这一现象, $\mathbf{4 0}$ 中的羰基距仲碳正离子中心更接 近, 7-endo-trig 环化过程比 5-endo 环化过程更容易进行, 所以 1,4-二氧杂环庚-2-烯比四氢呋喃类化合物更容易 生成.

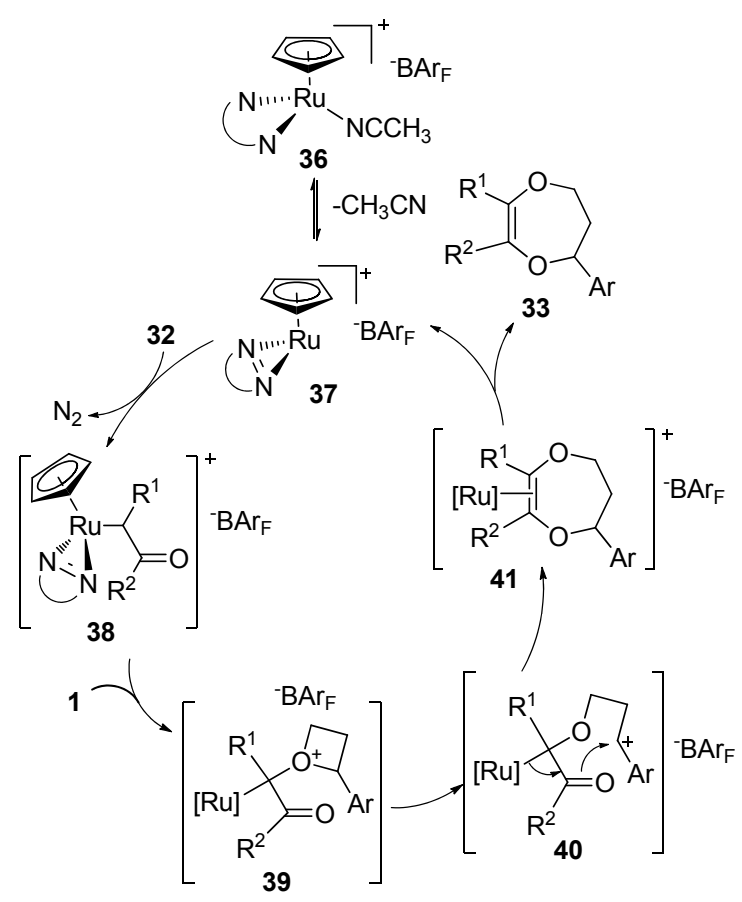

图式 $8 \mathrm{Ru}$ 催化扩环反应的反应机理

Scheme 8 Reaction mechanism of Ru-catalyzed ring expansion reaction

大环化合物的合成也可以由氧杂环丁烷和重氮化 合物的反应实现, 2011 年, Lacour 等 ${ }^{[29]}$ 报道了 $\alpha$-重氮- $\beta$ 酮酸酯 43 与氧杂环丁烷 42 在 $1 \mathrm{~mol} \% \mathrm{Rh}_{2}(\mathrm{OAc})_{4}$ 催化下 反应形成十五元大环化合物 $\mathbf{4 4}$ 的反应(Scheme 9). 该反 应在 $20{ }^{\circ} \mathrm{C}$ 的温和条件下进行, 反应过程中以氧杂环丁 烷 42 为溶剂. 多种烷基和烷氧基取代基的重氮酮酯化 合物 43 在该反应条件下都具有良好的耐受性，产物的 产率为 $55 \% \sim 84 \%$. 使用带有取代基的氧杂环丁烷也可 以进行该反应, 3,3-二甲基氧杂环丁烷 20a 和 3,3-二乙基 氧杂环丁烷 $20 b$ 可以分别以 $65 \%$ 和 $51 \%$ 的产率生成相应 的取代的十五元大环产物 45 和 46.

随后, 2014 年, Kitamura 等 ${ }^{[30]}$ 报道了重氮萗酮与氧 杂环丁烷在 $2.5 \mathrm{~mol} \% \mathrm{Pd}(\mathrm{OAc})_{2}$ 催化下反应生成十五元 大环化合物的反应(Scheme 10). 以氧杂环丁烷 42 为溶 剂, 在回流条件下重氮萘酮 47 和 48 与氧杂环丁烷 42

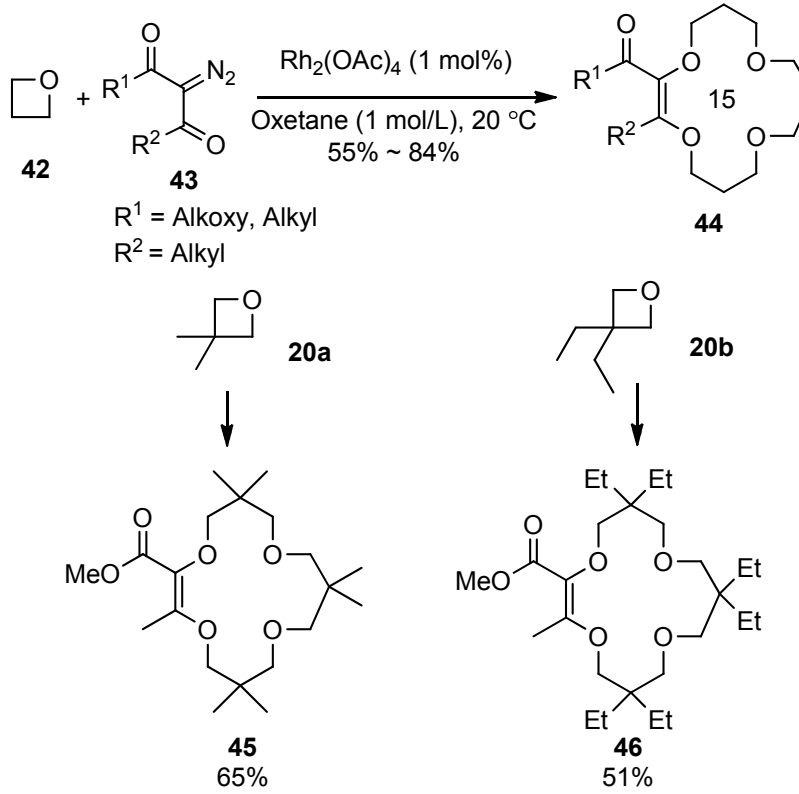

图式 9 重氮酮酯与氧杂环丁烷的反应

Scheme 9 Reaction of $\alpha$-diazo- $\beta$-oxoalkanoates with oxetanes 反应，生成十五元大环产物 49 的产率分别为 $66 \%$ 和 $26 \%$.

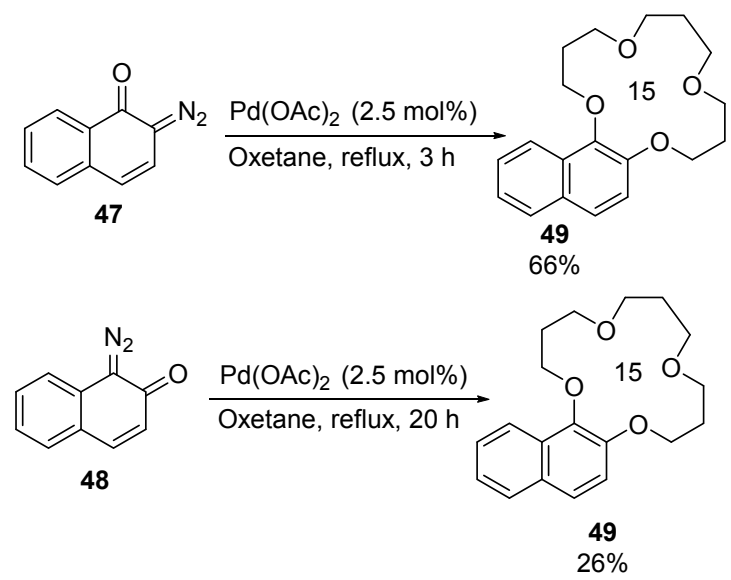

图式 10 重氮菜醌与氧杂环丁烷的反应

Scheme 10 Reaction of diazonaphthoquinones with oxetane

\section{2 氧杂环丁烷与磺酰基三唑的扩环反应}

$N$-磺酰基-1,2,3-三唑 50 是一类重要有机合成试剂. $N$-磺酰基-1,2,3-三唑是重氮亚胺 51 的前体，它们之间存 在平衡，而且在金属催化条件下 50 可以通过重氮亚胺 51 转化为亲电性的亚胺基卡宾 $\mathbf{5 2}^{[31]}$ (Scheme 11).

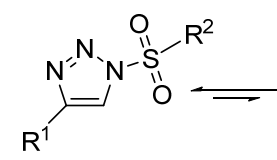

50

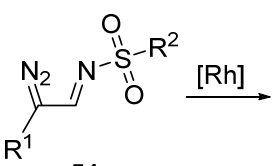

51

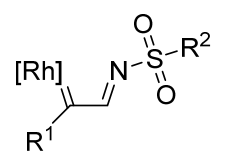

52
图式 11 由磺酰基三唑转化为金属卡宾

Scheme 11 Formation of metallocarbenes from $\mathrm{N}$-sulfonyltriazoles 
由于磺酰基三唑的化学性质和重氮化合物相似, 2017 年, Lacuor 等 ${ }^{[32]}$ 对 Rh(II)催化和热活化下磺酰基三 唑和氧杂环丁烷的扩环反应进行了深入研究. 通过控制 不同的反应条件或不同取代基的磺酰基三唑底物，可以 得到结构多样的氧杂环丁烷的扩环产物.

首先，使用 $1 \mathrm{~mol} \%$ 的 $\mathrm{Rh}_{2}(\mathrm{~S}-\mathrm{TCPTTL})_{4}(\mathbf{5 3})$ 作为催 化剂, 1 equiv. $N$-磺酰基-1,2,3-三唑 $\mathbf{5 0}$ 和 1.5 equiv.的 3,3二甲基氧杂环丁烷 20a 在二氯甲烷中于 $100{ }^{\circ} \mathrm{C}$ 反应 $3 \mathrm{~h}$ (Scheme 12). 分析反应体系的 ${ }^{1} \mathrm{H}$ NMR 谱发现了亚胺产 物 54. 但是 54 在硅胶或氧化铝上不稳定, 易分解. $\mathrm{LiAlH}_{4}$ 还原后得到了还原产物，两步合计得到了 $58 \%$ $80 \%$ 产率的磺酰胺甲基四氢呋喃 $\mathbf{5 5}$. 当 $\mathbf{5 5}$ 上 $\mathrm{R}^{1}$ 为强给 电子取代基乙氧基时, 可以稳定卡宾; 在无 $\mathrm{Rh}$ 催化剂 53 存在下, 仅通过热活化也可以得到 $50 \%$ 产率的相应 扩环产物, 但需要更长的反应时间.

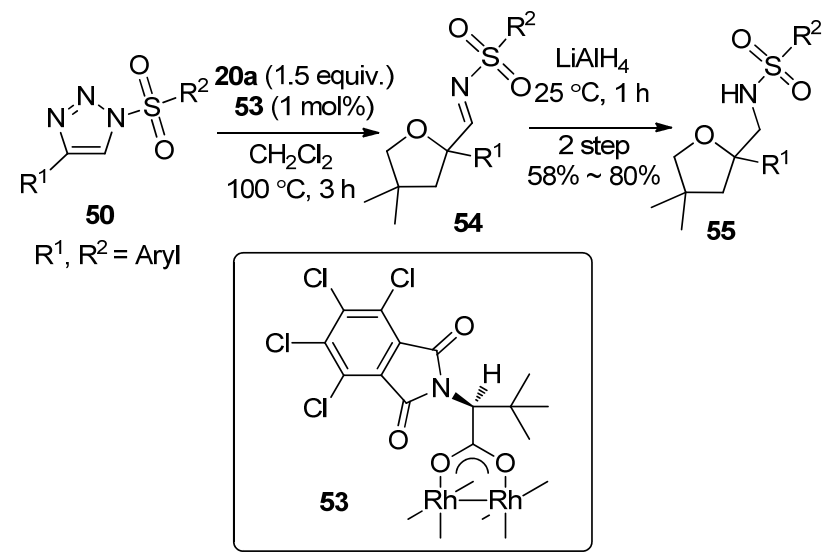

图式 12 低浓度下磺酰基三唑与氧杂环丁烷的反应

Scheme 12 Reaction of sulfonyltriazoles with 3,3-dimethyloxetane at low concentration

与之前的报道类似, 当使用 3,3-二甲基氧杂环丁烷 20a 作为溶剂时, 磺酰基三坐 50 在 $\mathrm{Rh}$ 催化剂 53 催化下, 可以 $19 \% \sim 64 \%$ 的产率生成十五元三氧氮杂大环化合物 56 (Scheme 13).

当使用甲磺酰基三唑 57 时, 磺酰基和氨基会参与 环化过程, 生成十一元杂环 58 和十三元杂环 $\mathbf{5 9}$

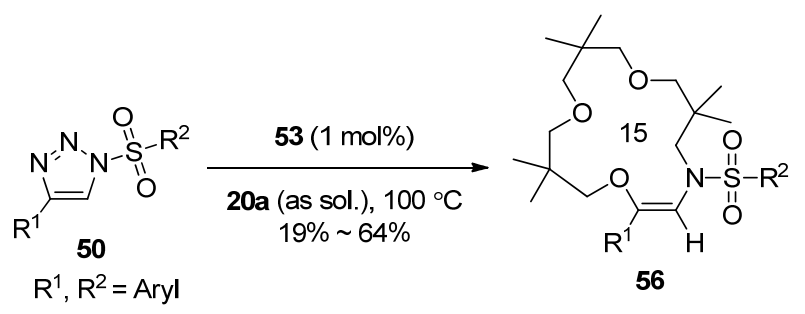

图式 13 高浓度下磺酰基三唑与氧杂环丁烷的反应 Scheme 13 Reaction of sulfonyltriazoles with 3,3-dimethyloxetane at high concentration
(Scheme 14). 十三元环化合物 59 中含有环内亚磺酸胺 酯基团, 使用 3,3-二甲基氧杂环丁烷 20a 作为溶剂, 甲 磺酰基三唑 57 在 $\mathrm{Rh}$ 催化剂 53 催化下，可以生成 48\% $61 \%$ 产率的十三元杂环 59 , 但该反应中总会伴随 10\% $20 \%$ 的十五元杂环产物 56 的存在.
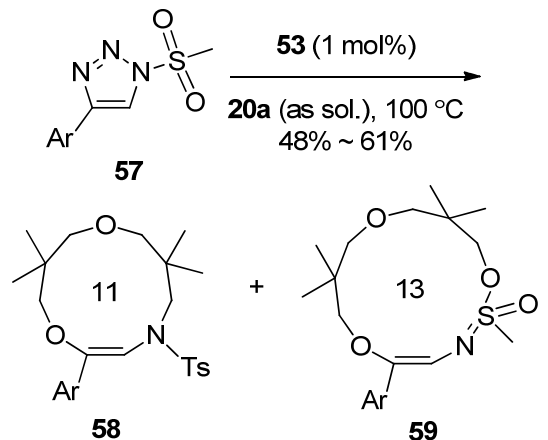

图式 14 甲磺酰基三唑与氧杂环丁烷的反应

Scheme 14 Reaction of methanesulfonyl triazoles with 3,3,-dimethyloxetane

Scheme 15 提出了上述反应的反应机理. 在 $\mathrm{Rh}(\mathrm{II})$ 催化剂催化下, $N$-磺酰基三唑 $\mathbf{5 0}$ 释放氮气生成亚胺基金 属卡宾 52, 52 具有亲电性, 可以与一分子的氧杂环丁烷 反应形成氧鑤叶立德中间体 $\mathbf{6 0}$. 由于 $\mathbf{6 0}$ 的环张力作用,<smiles>[R]OSN=CC([R])[O+]1CCC1</smiles>

50

52

60<smiles>[R20]O[Sb]N=CC1([R])CCCO1</smiles>

1,2-shift

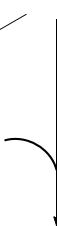

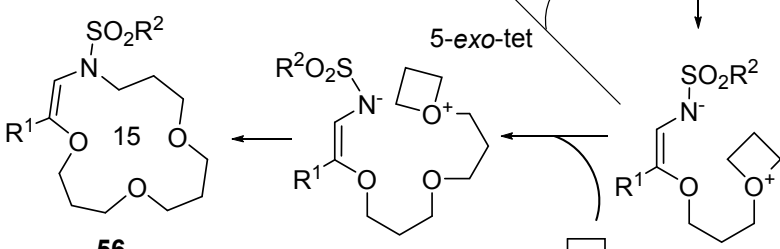

56

62

61<smiles>[R]OS(=O)N1/C=C(/[R])OCCCOCCCO[SH]([R])([O-])=N/C=C(/[R])OCCCO1</smiles>

59

58

图式 15 磺酰基三唑与氧杂环丁烷反应的反应机理 Scheme 15 Reaction mechanism of sulfonyltriazoles with oxetane 
在低浓度的氧杂环丁烷条件下, 更容易进行分子内 1,2迁移形成 54; 在高浓度条件下, 60 更容易和大量存在的 氧杂环丁烷继续反应生成中间体 61. 61 可以通过 5-exo-tet 环化再次生成 54, 或分别通过 11-endo-tet 或 9-endo-tet 环化生成 59 和 58. 61 也可以和第三分子的氧 杂环丁烷反应生成加成中间体 62 , 然后被末端氮原子 分子内亲核进攻, 生成最终产物 56.

\section{2 环加成反应扩环}

\section{1 分子间环加成}

环加成反应是扩环反应中非常常见和有效的途径. 1999 年, Alper 等 ${ }^{[33]}$ 报道了 2-乙烯基氧杂环丁烷和碳二 酰亚胺或异氰酸酯的环加成反应(Scheme 16). 0 价 Pd 催 化剂和膦配体催化下, 2-乙烯基氧杂环丁烷 63 与碳二酰 亚胺 64 或异氧酸酯 65 在四氢呋喃溶剂和氮气保护条件 下反应，生成产率为 $17 \% \sim 98 \%$ 的相应 1,3-噁嗪类化合 物 66. 双环乙烯基氧杂环丁烷 67 与碳二酰亚胺或异氰 酸酯也可以反应, 但反应需要加压且需要更多的钯催化 剂. Pd 催化的双环乙烯基氧杂环丁烷与碳二酰亚胺或异 氭酸酯可以进行高立体选择性的环加成反应，只得到相 应的顺式双环 1,3-噁嗪类化合物 68, 产率为 43\% 98\%。 反应通过 $\pi$-烯丙基-钯中间体 69 进行, 该中间体是将乙 烯基氧杂环丁烷加到钯络合物中, 然后中间体 69 与异 氭酸酯或碳二酰亚胺反应生成中间体 $\mathbf{7 0}$, 进而通过环 化过程形成 1,3-噁嗪类化合物 66. 当使用异㲵酸酯时, 反应产率较低, 可能是由于相对于环化速率而言, 异氭 酸酯的二聚速率比碳二酰亚胺的二聚速率更快.

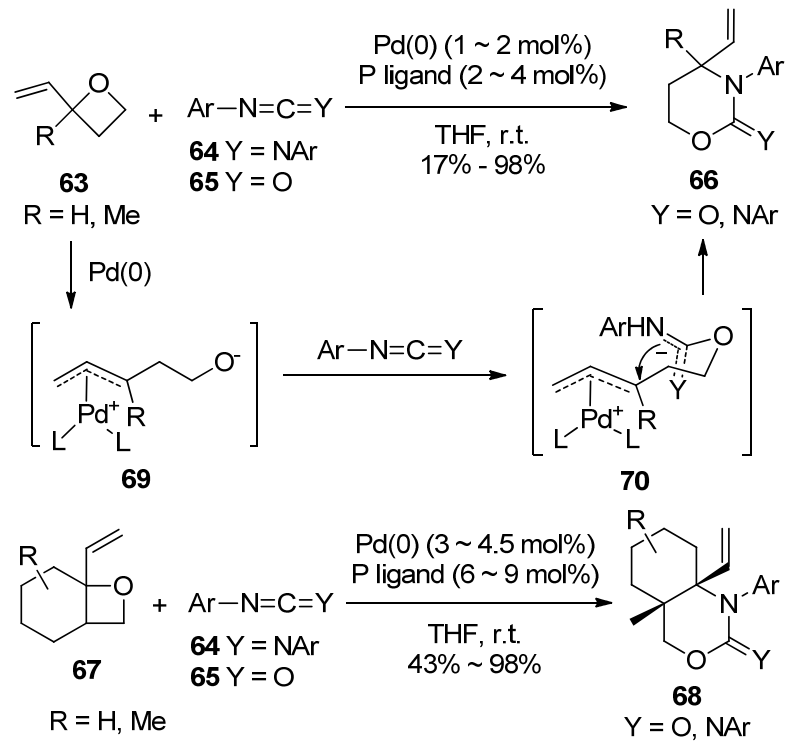

图式 16 乙烯基氧杂环丁烷和碳二酰亚胺或异氭酸酯的反应 Scheme 16 Reactions of vinyloxetanes with carbodiimides and isocyanates
以前, 环己酮的烯醇锂或溴化镁盐均无法和氧杂环 丁烷发生扩环反应 ${ }^{[34]}$. 2005 年, Posner 等 ${ }^{[35]}$ 实现了低温 条件下三氟化硼乙醚催化的 $\alpha$-硅烷基环烷酮烯醇硅醚 71 和氧杂环丁烷 42 的反应，以 $54 \% \sim 67 \%$ 的产率得到 了六元氧杂环产物 72 (Scheme 17). 应用该六元氧杂环 产物 72 实现了多种大环内酯的合成.

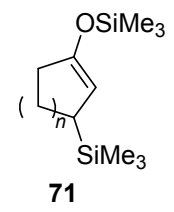

$n=1,2$

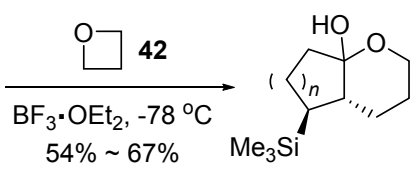

72
图式 17 烯醇硅醚与氧杂环丁烷的反应

Scheme 17 Reaction of silyl enol ethers with oxetane

2014 年, 刘瑞雄等 ${ }^{[36]}$ 实现了在 $\mathrm{Ag} / \mathrm{Au}$ 协同催化下, $N$-炔基酰胺 73 与 2-芳基氧杂环丁烷 1 发生 $[4+2]$ 环加 成, 得到 6-氨基-3,4-二氢- $2 H$-吡喃衍生物 74 的反应 (Scheme 18). 由于氧杂环丁烷的氧原子具有亲核性, 金 属一烯酮亚胺中间体 75 具亲电性, 因此该反应具有极好 的区域选择性，氧杂环丁烷的氧原子对金属一烯酮亚胺 中间体 75 亲核进攻形成 $\mathrm{Au}(\mathrm{I})$ 或 $\operatorname{Ag}(\mathrm{I})$ 烯基中间体 76, 然后芳基加速其开环，生成稳定的芳甲基正离子 77, 分 子内关环生成中间体 $\mathbf{7 8}$, 消除金属得到最终的六元杂 环产物 74. 多种芳基氧杂环丁烷和芳基酰胺进行反应, 得到了产率为 $64 \% \sim 88 \%$ 的不同结构的产物 74 .

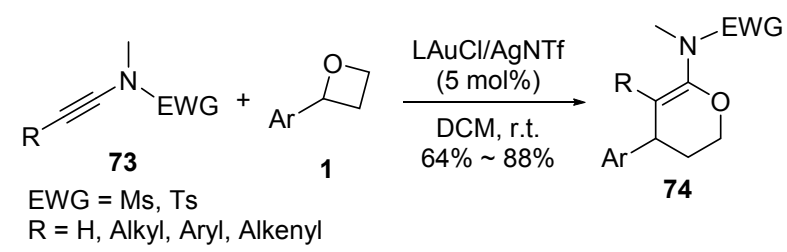<smiles>[R]C#CN(C)C#[R]C(C)C</smiles>

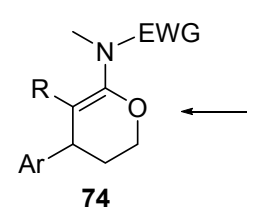

图式 $18 N$-炔基酰胺与氧杂环丁烷的反应
在上述研究的基础上, 2016 年, 刘瑞雄等 ${ }^{[37}$ 进一步 报道了在 $\mathrm{Ag} / \mathrm{Au}$ 协同催化下, 丙炔酸叔丁酯 79 与 2-芳 
基氧杂环丁烷 1 发生 $[4+4]$ 环加成, 得到八元环内酯 80 的反应(Scheme 19). 多种 2-芳基氧杂环丁烷 1 和不同取 代的丙炔酸叔丁酯 79进行反应, 得到产率为 $62 \% \sim 82 \%$ 的不同八元环内酯产物 80 .

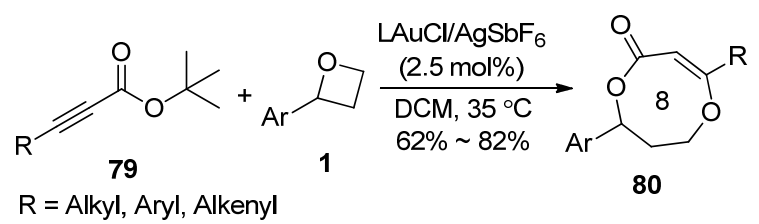

图式 19 丙炔酸叔丁酯与氧杂环丁烷的反应

Scheme 19 Reaction of tert-butyl propiolates with oxetanes

2018 年, Zhao 等 ${ }^{[38]}$ 通过 Pd-SIPHOX 配合物催化的 2-芳 基-2-乙烯基氧杂环丁烷 81 与氮杂二烯 82 的 $[6+4]$ 环加 成反应，合成了含有苯并呋喃或吲哚结构的十元杂环化 合物 83 (Scheme 20). 在反应过程中, 除了目标产物十 元杂环产物外，还会生成乙烯基氧杂环丁烷自身扩环的 副产物 84, 以及通过从 Pd- $\pi$-烯丙基中间体 $\beta$-氢消除产 生的二烯副产物 85 . 较高的反应温度有利于减少副产 物的生成. 使用更大体积的配体 86 可以更高产率和更 高对映选择性得到十元杂环产物 83. 分别对多种氮杂 二烯和氧杂环丁烷的结构进行拓展，以 $53 \% \sim 99 \%$ 的产 率得到了 $e e$ 值为 $87 \% \sim 99 \%$ 的不同含有苯并呋喃或吲 哚结构的十元杂环化合物 83.

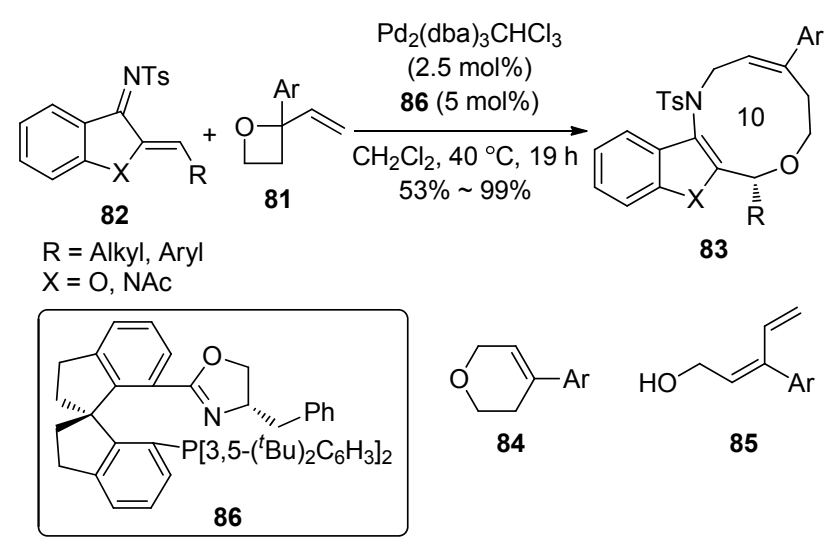

图式 20 氮杂二烯和乙烯基氧杂环丁烷的反应

Scheme 20 Reaction of azadienes with vinyloxetanes

2019 年, 张勇健等 ${ }^{[39]}$ 通过 Pd 催化的乙烯基氧杂环 丁烷与甲醛的不对称 $[4+2]$ 环加成合成了 1,3-二噁烷 89 (Scheme 21). 使用 $2.5 \mathrm{~mol} \%$ 的 $\mathrm{Pd}_{2}\left(\mathrm{dba}_{3} \cdot{ }^{\circ} \mathrm{CHCl}_{3}\right.$ 和 10 $\mathrm{mol} \%$ 亚磷酰胺酯配体 $\mathbf{8 8}$ 作为催化剂, 乙醚作为溶剂, $40{ }^{\circ} \mathrm{C}$ 乙烯基氧杂环丁烷与过量甲醛水溶液反应, 可以 得到 4-取代-4-乙烯基-1,3-二嚚烷 89. 对于 2-芳基-2-乙 烯基氧杂环丁烷 87, 可以 29\% 91\%的产率, 52\% 99\%的 ee 值得到相应的产物 89; 而对于 2-烷基-2-乙烯 基氧杂环丁烷 87 , 反应效果则大大降低.
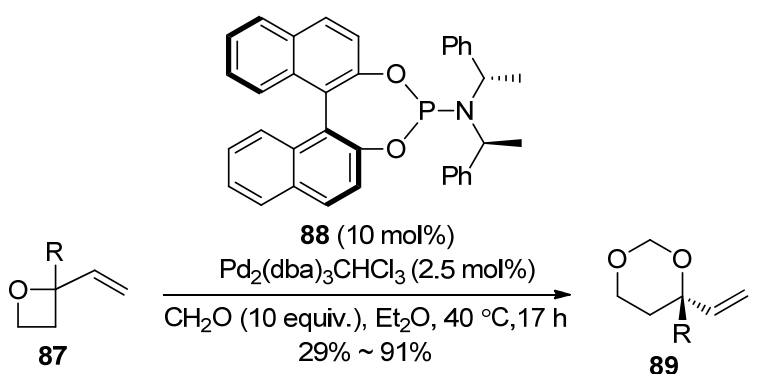

$\mathrm{R}=$ Alkyl, Aryl

89

图式 21 甲醛和 2-乙烯基氧杂环丁烷的反应

Scheme 21 Reaction of formaldehyde with 2-vinyloxetanes

在使用苯并 $[d][1,3]$ 噁嗪酮 90 构建多种杂环化合物 的研究基础上 ${ }^{[40-41]}, 2020$ 年, Shibata 等 ${ }^{[42]}$ 实现了非脱羧 的 Pd 催化苯并 $[d][1,3]$ 悪嗪酮 90 和 2-乙烯基氧杂环丁烷 87 的 $[6+6]$ 环加成反应, 得到了含三氟甲基的十二元杂 环产物 91 (Scheme 22). 在他们之前的研究中, Pd 催化 下苯并 $[d][1,3]$ 硻嗪酮 90 在与硫叶立德或碳酸乙烯基亚 乙酯的反应时会发生脱羧现象 ${ }^{[40-41]}$; 而在与 2-乙烯基氧 杂环丁烷 87 反应时，却没有发生脱羧现象. 用 $5 \mathrm{~mol} \%$ 的 $\operatorname{Pd}\left(\mathrm{PPh}_{3}\right)_{4}$ 作为催化剂, 1,4-二氧六环为溶剂, 常温下 多种苯并 $[d][1,3]$ 㷂嗪酮 90 和 2 -乙烯基氧杂环丁烷 87 反 应，以 45\% 98\%的产率得到含三氟甲基的十二元杂环 化合物 91, 但这个反应所需的反应时间很长. 当使用 4甲基苯并噁嗪酮 92 代替苯并噁嗪酮 90 与 2-乙烯基氧杂 环丁烷 87 反应时, 尽管将温度提升至较高温度 $\left(80{ }^{\circ} \mathrm{C}\right)$, 但仍然只能以较低的收率(27\% 36\%)得到所需的甲基 取代的十二元杂环产物 93. 通过液相色谱一质谱联用技 术(LC-MS)确定反应同样是经历 Pd- $\pi$-烯丙基中间体.

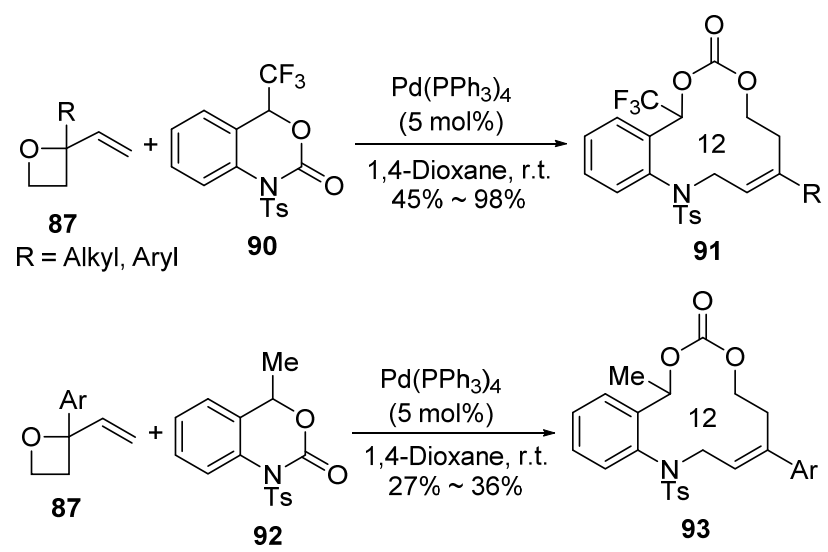

图式 22 苯并噁嗪酮和乙烯基氧杂环丁烷的反应

Scheme 22 Reaction of benzoxazinones with vinyloxetanes

\section{2 分子内环加成}

2012 年, Njardarson 等 ${ }^{[43]}$ 在 $1 \mathrm{~mol} \% \mathrm{Cu}(\mathrm{OTf})_{2}$ 或 10 mol\%手性磷酰胺酯的催化下, 通过 2-乙烯基氧杂环丁 
烷 87 自身扩环得到 3,6-二氢- $2 H$-吡喃衍生物 84 (Scheme $23) . \mathrm{Cu}(\mathrm{OTf})_{2}$ 与 2-乙烯基氧杂环的氧原子配位生成四元 环中间体 94, 然后 94 开环生成中间体 95, 再经过 6-endo-trig 环化得到 3,6-二氢- $2 H$-吡喃衍生物 84, 产率 为 78\% 98\%. 对于 2,2-二乙烯基氧杂环丁烷 96, 当使 用手性磷酰胺酯 99 作为催化剂时, 尽管与手性铜催化 剂 98 催化相比, 产物产率变低, 但手性磷酰胺酯催化得 到的二氢吡喃类化合物 97 的 $e e$ 值最高, 可以达到 $90 \%$.
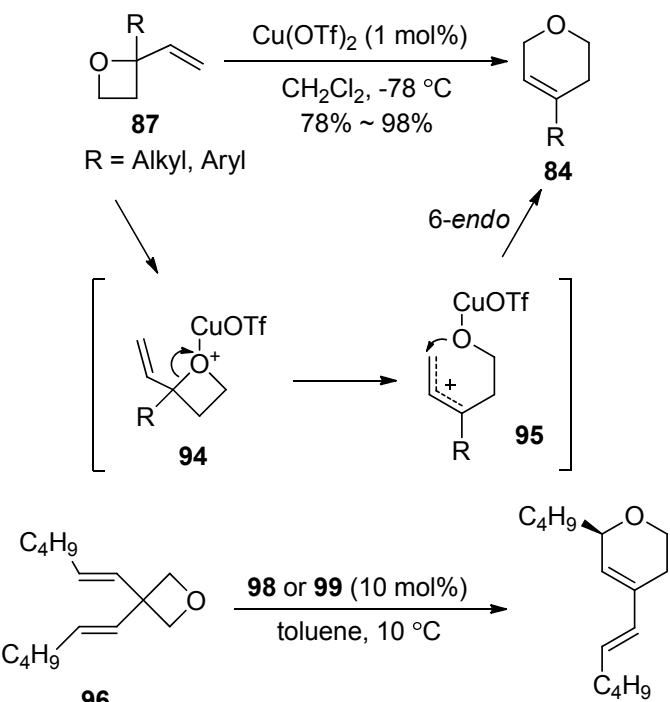

96

97

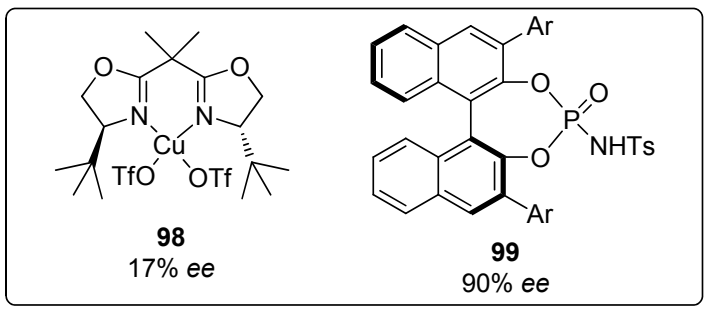

图式 $23 \mathrm{Cu}$ 催化的乙烯基氧杂环丁烷分子内扩环反应

Scheme $23 \mathrm{Cu}$-catalyzed intramolecular ring expansion of vinyloxetanes

2012 年, Gagosz 等 ${ }^{[44]}$ 报道了在吡啶氧化物存在下, $\mathrm{Cu}(\mathrm{I})$ 催化的 2-乙炔基氧杂环丁烷环 100 的分子内扩环 反应(Scheme 24), 通过改变吡啶氧化物的取代基, 可以 实现二氢呋喃-2-甲醛 101 或六元环内酯 102 产物的选择 性合成. 从机理上看, 二氢呋喃-2-甲醛或六元环内酯的 生成可能源自烯丙氧基吡啶鎓中间体 103 和 104. 实验 证明, 更缺电子的 3-溴吡啶氧化物 105, 是 5-exo-trig 环 化中较好的离去基团, 更有利于二氢呋喃-2-甲醛 101 的 形成. 相反, 使用富电子的氧化剂 4-甲氧基吡定氧化物 106 有助于以 6-endo 的方式环化, 仅能生成六元环内酯 产物 102. 分别对两种产物进行了底物拓展, 二氢呋喃2-甲醛产物 101 的产率为 $72 \% \sim 88 \%$, 六元环内酯产物 102 的产率可达 67\% 89\%.
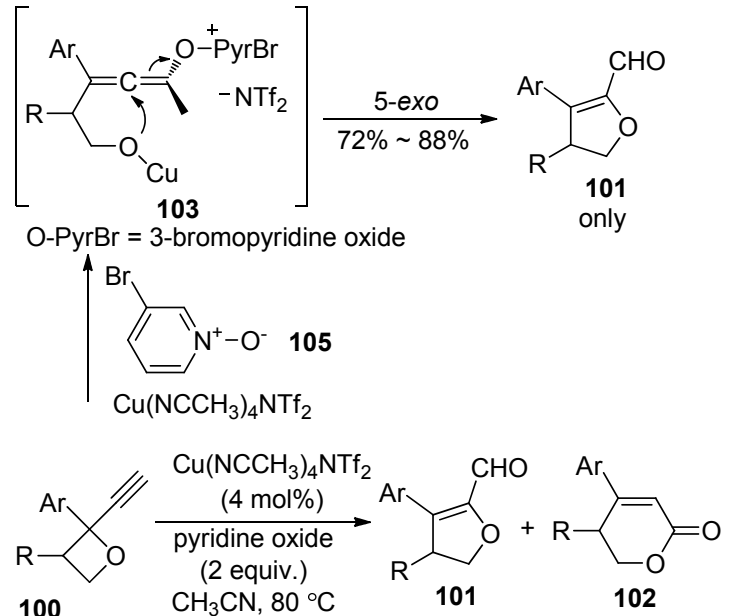

100 $\mathrm{CH}_{3} \mathrm{CN}, 80^{\circ} \mathrm{C}$ 102<smiles>COc1cc[n+]([O-])cc1</smiles>

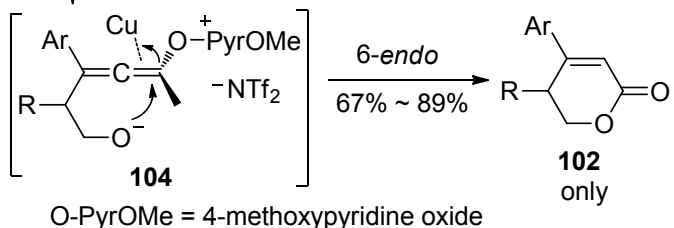

图式 $24 \mathrm{Cu}(\mathrm{I})$ 催化炔基氧杂环丁烷扩环合成二氢呋喃-2-甲 醛和六元环内酯

Scheme $24 \mathrm{Cu}(\mathrm{I})$-catalyzed ring expansions of 2-ethynyloxetane to dihydrofuran-2-carbaldehydes and six-membered lactones

\section{3 亲核扩环反应}

亲核性扩环是小杂环化合物的常见反应，如三元杂 环通过亲核性扩环可以得到四元环产物 ${ }^{[45]}$. 氧杂环丁 烷的亲核扩环反应，一般是亲核试剂先亲核进攻氧杂环 丁烷 2 位碳原子, 促使氧杂环丁烷开环, 经过后续的转 化，最后发生分子内亲核关环，实现扩环反应.

Baba 等 ${ }^{[46-49]}$ 于 1985 年就报道了 $\mathrm{Sn}$ 催化的氧杂环丁 烷 42 和二氧化碳、异氰酸酯的亲核扩环反应(Scheme 25). 在与二氧化碳反应时, 使用 $\mathrm{Bu}_{3} \mathrm{SnI}$ 和大量 $\mathrm{Bu}_{3} \mathrm{P}=\mathrm{O}$ 混合催化，长时间反应可以减少聚合产物的生成，高压 条件下，可以 $74 \%$ 的产率生成三亚甲基碳酸酯(TMC) 107. 使用 $\mathrm{Bu}_{3} \mathrm{SnI}$ 和大量 $N, N, N^{\prime}, N^{\prime}, N^{\prime \prime}, N^{\prime}$-六甲基磷酰胺 (HMPA)混合催化, 没有聚合产物生成, 长时间反应可以 定量转化为三亚甲基碳酸酯 TMC 107. 使用 $\mathrm{Ph}_{4} \mathrm{SbI}$ 催 化，高压条件下, $100{ }^{\circ} \mathrm{C}$ 下反应 $4 \mathrm{~h}$ 即可得到 $96 \%$ 产率的 三亚甲基碳酸酯 $\mathrm{TMC}$ 107. 氧杂环丁烷也可以与等物质 的量的异氰酸酯反应, 以 $11 \% \sim 87 \%$ 的产率生成六元酰胺 内酯 112. 当使用 $\mathrm{Ph}_{2} \mathrm{SnI}_{2}$ 和 HMPA 混合催化时, 带有取 代基的氧杂环丁烷 109 也可和异氰酸酯反应，短时间反 应就以 $46 \% \sim 100 \%$ 的产率得到取代六元酰胺内酯 110. 

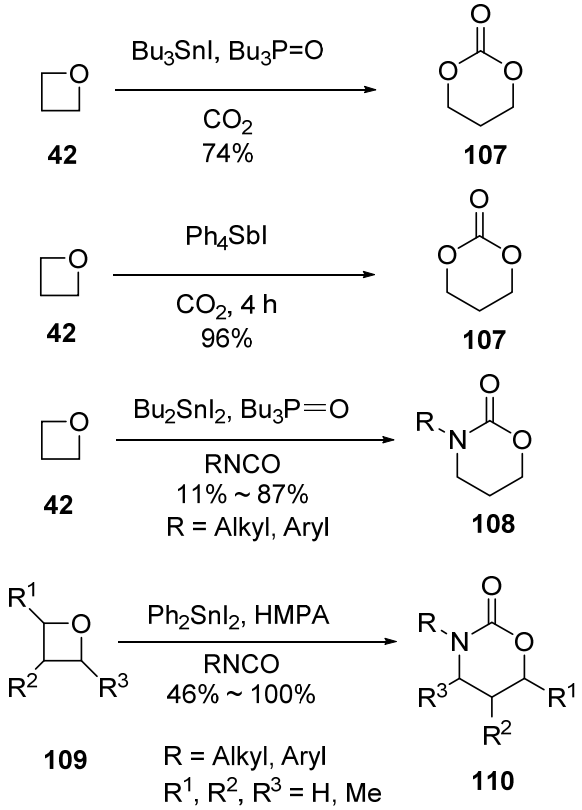

图式 25 氧杂环丁烷和 $\mathrm{CO}_{2}$ 或异氰酸酯的反应

Scheme 25 Reactions of oxetane with $\mathrm{CO}_{2}$ and isocyanates

在之前的研究基础上, Baba 等 ${ }^{[50]}$ 在 1988 年报道了 氧杂环丁烷 42 和二苯基烯酮 111 的反应(Scheme 26). 使 用多种 $\mathrm{Sb}$ 催化剂和不同溶剂组合, 最高以 $80 \%$ 的产率 得到六元环内酯 112. 而当使用 $\mathrm{Bu}_{2} \mathrm{SnI}_{2}-\mathrm{HMPA}$ 催化组 合时, 以 $24 \%$ 的总产率生成化学选择性 $1: 1$ 的六元环 内酯 112 和 2-二苯基亚甲基-1,3-二氧六环 113.

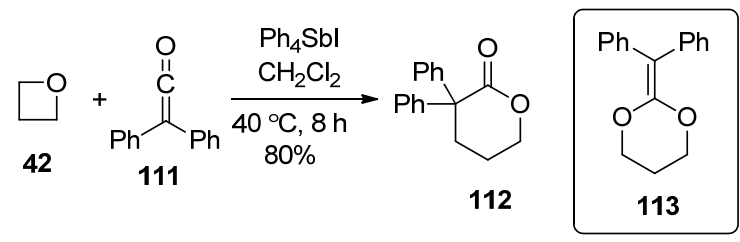

图式 26 氧杂环丁烷和烯酮的反应

Scheme 26 Reactions of oxetane with ketene

2006 年, Darensbourg 等 ${ }^{[51-54]}$ 报道了 $\mathrm{Cr} 、 \mathrm{Al}$ 或 $\mathrm{Co}$ 等金属 Salen 配合物和 $n-\mathrm{Bu}_{4} \mathrm{NCl}$ 协同催化的氧杂环丁烷 42 和二氧化碳的反应(Scheme 27). 该反应主要生成了 聚合物, 当使用 $0.15 \mathrm{~mol} \%$ 的 Cr-Salen 配合物 114 和 1 equiv. $n-\mathrm{Bu}_{4} \mathrm{NCl}$ 协同催化, 在高温高压条件下, 仅以 22\%的产率生成三亚甲基碳酸酯 TMC 107.

为了减少聚合物的生成, 提升三亚甲基碳酸酯 $\mathrm{TMC} 107$ 的转化率, 2010 年, 他们 ${ }^{[55]}$ 又提出了 $\mathrm{VO}(\mathrm{acac})_{2}$ 催化的氧杂环丁烷和二氧化碳的反应(Scheme 28). 经过一系列优化, 使用 $5 \mathrm{~mol} \% \mathrm{VO}(\mathrm{acac})_{2}$ 和 1 equiv. 的 $n-\mathrm{Bu}_{4} \mathrm{NBr}$ 协同催化, 高压 $60{ }^{\circ} \mathrm{C}$ 下应 $8 \mathrm{~h}$, 氧 杂环丁烷 42 以 $95 \%$ 的转化率转化为三亚甲基碳酸酯 TMC 107, 没有聚合物生成. 对于含取代基的氧杂环丁

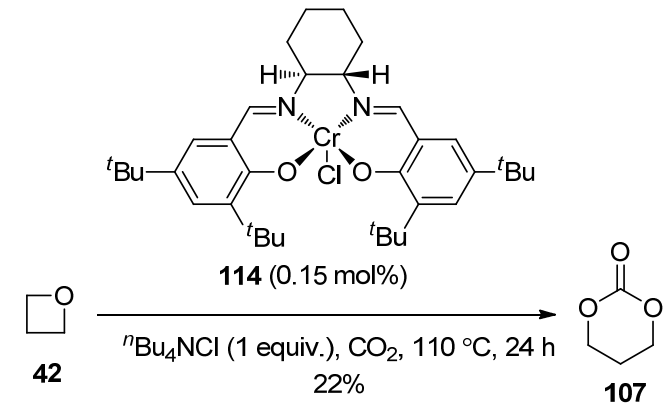

图式 27 Cr-Salen 配合物催化的氧杂环丁烷与 $\mathrm{CO}_{2}$ 的反应 Scheme 27 Cr-Salen complex-catalyzed reaction of oxetane and $\mathrm{CO}_{2}$

烷，3-乙基氧杂环丁烷-3-甲醇 20c 和 3,3-二甲基氧杂环 丁烷 20a 在相似的反应条件下，与二氧化碳反应时，得 到了 $100 \%$ 选择性的扩环产物, 但反应速率和产率比不 含取代基的氧杂环烷 $\mathbf{4 2}$ 要低得多.

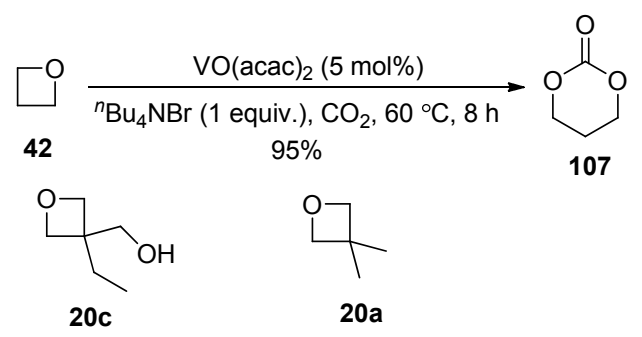

图式 $28 \mathrm{VO}(\mathrm{acac})_{2}$ 催化的氧杂环丁烷与 $\mathrm{CO}_{2}$ 的反应 Scheme 28 Reaction of oxetane and $\mathrm{CO}_{2}$ catalyzed by $\mathrm{VO}(\mathrm{acac})_{2}$

2012 年, Kleij 等 ${ }^{[56]}$ 深入研究了氨甲基三酚金属络 合物催化的氧杂环丁烷和二氧化碳的反应(Scheme 29). 当使用氨甲基三酚铁络合物 $\mathbf{1 1 5}$ 催化, 卤化四正丁基铵 作助催化剂, 氧杂环丁烷 $\mathbf{4 2}$ 和二氧化碳在丁酮(MEK) 中 $85{ }^{\circ} \mathrm{C}$ 反应 $18 \mathrm{~h}$, 可以 $98 \%$ 的产率得到三亚甲基碳酸 酯 TMC 107, 使用碘化物亲核试剂碘化四丁基铵(TBAI) 时产率高于溴化物亲核试剂溴化四丁基铵(TBAB). 对 于带有取代基的氧杂环丁烷, 仅能以很低的产率得到扩 环产物，延长反应时间可以略微提升产率.

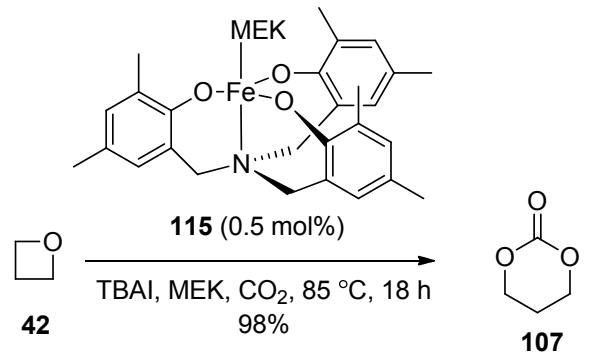

图式 29 氨基三酚铁络合物催化的氧杂环丁烷与 $\mathrm{CO}_{2}$ 的反应 Scheme 29 Iron amino triphenolate complex-catalyzed reaction of oxetane and $\mathrm{CO}_{2}$ 
2013 年, 他们 ${ }^{[57]}$ 改用氨甲基三酚铝络合物 116 催化 这个反应(Scheme 30), 与氨甲基三酚铁络合物 $\mathbf{1 1 5}$ 反应 结果类似, 氧杂环丁烷 $\mathbf{4 2}$ 反应后可以得到 $95 \%$ 产率的 三亚甲基碳酸酯 TMC 107, 但带有取代基的氧杂环丁烷 反应产率仍然很低.

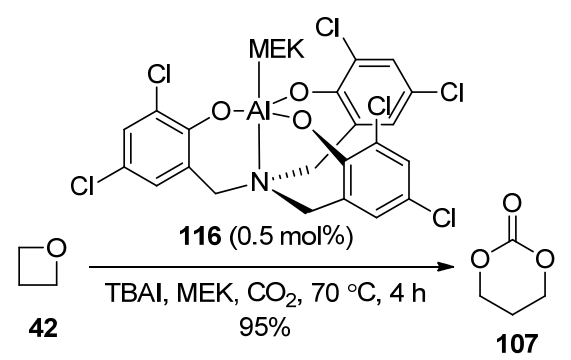

图式 30 氨基三酚铝络合物催化的氧杂环丁烷与 $\mathrm{CO}_{2}$ 的反应 Scheme 30 Reaction of oxetane and $\mathrm{CO}_{2}$ catalyzed by aluminum amino triphenolate complex

为了提高带有取代基的氧杂环丁烷和二氧化碳反 应的产率, 2015 年, 该课题组 ${ }^{[58]}$ 又使用 $2.5 \mathrm{~mol} \%$ 含大位 阻取代基的氨甲基三酚铝络合物 117 和 $5 \mathrm{~mol} \% \mathrm{TBAB}$ 协同催化, 高压条件下, 含取代基的氧杂环丁烷 118 和 二氧化碳在丁酮(MEK)中反应(Scheme 31). 该反应是目 前仅有的经过深入细致研究的多取代氧杂环丁烷和二 氧化碳的反应. 通过调整反应温度和时间，以 $49 \%$ 92\%的产率得到多种六元碳酸酯 119 .

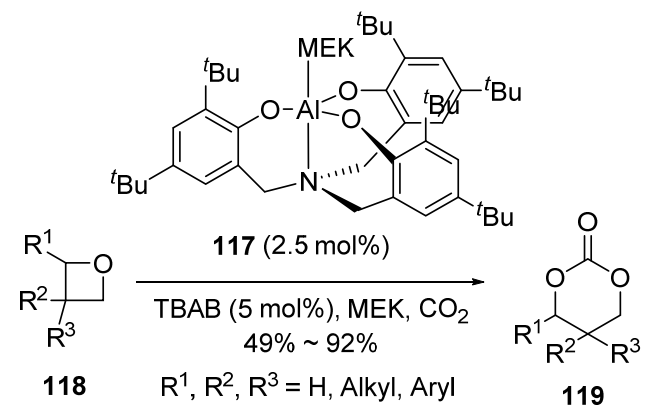

图式 31 氨基三酚铝络合物催化的多取代氧杂环丁烷与 $\mathrm{CO}_{2}$ 的反应

Scheme 31 Reaction of polysubstituted oxetane and $\mathrm{CO}_{2}$ catalyzed by aluminum amino triphenolate complex

2015 年, Wijayantha 等 ${ }^{[59]}$ 将电化学引入氧杂环丁烷 和二氧化碳的反应中(Scheme 32). 使用铜作阴极, 镁作 阳极, TBAI 作电解质, 电流控制在 $90 \mathrm{~mA}$, 氧杂环丁烷 42 和二氧化碳在乙腈中 $75{ }^{\circ} \mathrm{C}$ 反应 $6 \mathrm{~h}$. 尽管该反应对 扩环产物 107 的选择性不是 $100 \%$, 仍然会生成聚合物, 但最终能够以 $96 \%$ 的产率得到三亚甲基碳酸酯 $\mathrm{TMC}$ 107.

在深入研究氧杂环丙烷和二氧化碳反应的同时, 代 斌等也在 2017 年 ${ }^{[60]}$ 和 2018 年 ${ }^{[6]]}$ 分别报道了氧杂环丁烷

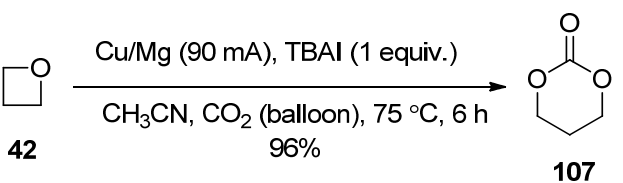

图式 32 电催化的氧杂环丁烷与 $\mathrm{CO}_{2}$ 的反应

Scheme 32 Electrocatalytic reaction of oxetane and $\mathrm{CO}_{2}$

和二氧化碳的反应(Scheme 33). 使用结构复杂的催化 剂 118 和 $119,80{ }^{\circ} \mathrm{C}$ 反应 $24 \mathrm{~h}$, 可分别以 $67 \%$ 和 $37 \%$ 的 产率得到三亚甲基碳酸酯 TMC 107.
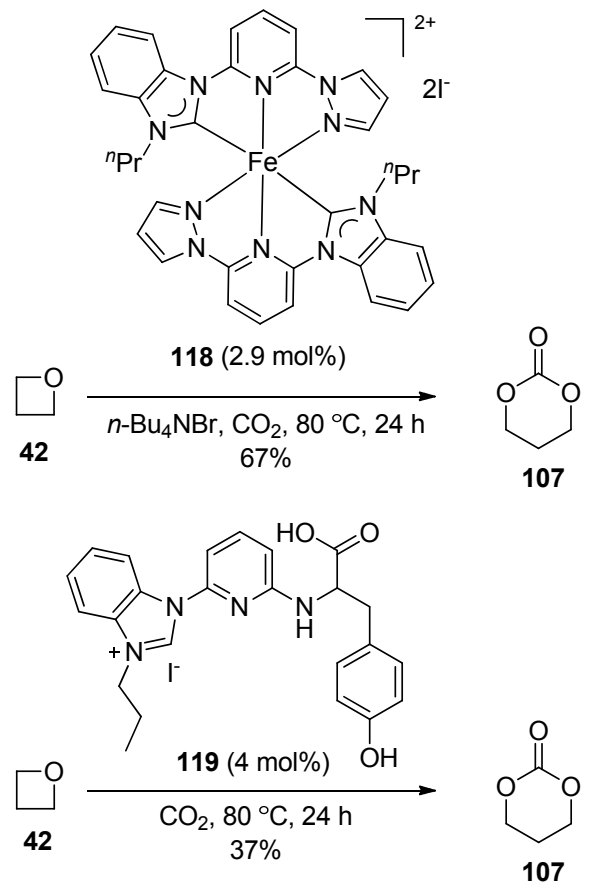

图式 33 氧杂环丁烷与 $\mathrm{CO}_{2}$ 的反应

Scheme 33 Reaction of oxetane and $\mathrm{CO}_{2}$

除了与二氧化碳等化合物的亲核反应外, 2010 年, Schreiner 等 ${ }^{[62]}$ 实现了三甲基碘化亚砜和氧杂环丁烷的 亲核扩环反应(Scheme 34), 三甲基碘化亚砜在碱的作 用下可以生成二甲亚砜亚甲基叶立德 122 . 二甲亚砜亚

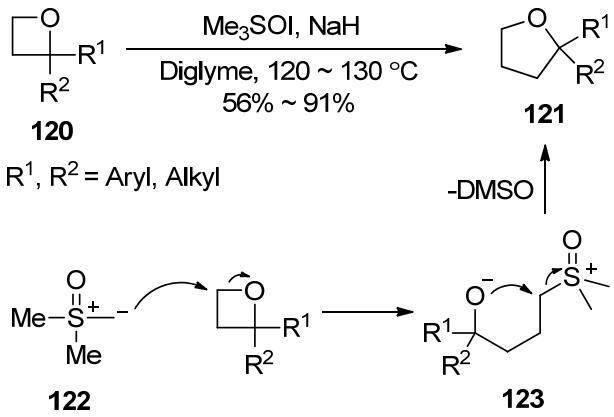

图式 34 硫叶立德和氧杂环丁烷的扩环反应 Scheme 34 Ring expansion reaction of sulfur ylide and oxetanes 
甲基叶立德进攻 2,2-二取代氧杂环丁烷 120 位阻较小的 一侧，发生亲核开环反应生成中间体 123, 带负电荷的 氧原子再分子内进攻与带正电的硫原子相连的碳原子 发生分子内 $\mathrm{S}_{\mathrm{N}} 2$ 亲核取代反应, 取代掉二甲基亚砜, 最 终得到扩环的五元环产物取代呋喃衍生物 121. 多种烷 基和芳基取代的氧杂环丁烷都有较好的反应效果, 产率 为 $56 \% \sim 91 \%$.

\section{4 其他扩环反应}

2019 年, Miura 等 ${ }^{[63]}$ 报道了镍催化的 $N$-(喹啉-8-基) 苯甲酰胺 124 与氧杂环丁烷的扩环反应(Scheme 35). 使 用 $\mathrm{NiCl}_{2}\left(\mathrm{PEt}_{3}\right)_{2}$ 作催化剂, $N, N$-二甲基甲酰胺(DMF)为溶 剂, 在 124 和氧杂环丁烷 $\mathbf{4 2}$ 的反应体系中加入分子笁和 三乙胺添加剂, $160{ }^{\circ} \mathrm{C}$ 反应 $22 \mathrm{~h}$, 以 $31 \% \sim 80 \%$ 的产率 得到苯并七元环内酯 $\mathbf{1 2 5}$. 当使用 $(S)$-2-芐基氧杂环丁烷 1f 与 124a 反应时, 以 54\%的产率得到了手性保留的七 元环内酯 126. 3-苯基氧杂环丁烷 127 与 $124 \mathrm{a}$ 反应, 仅 得到了 $57 \%$ 产率的七元环内酯 $\mathbf{1 2 8}$. 而当使用位阻较大 的 2,2-和 3,3-二取代的氧杂环丁烷时, 均不能发生反应.

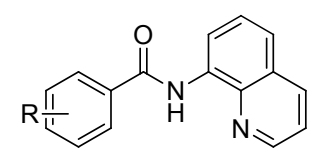

124

124a
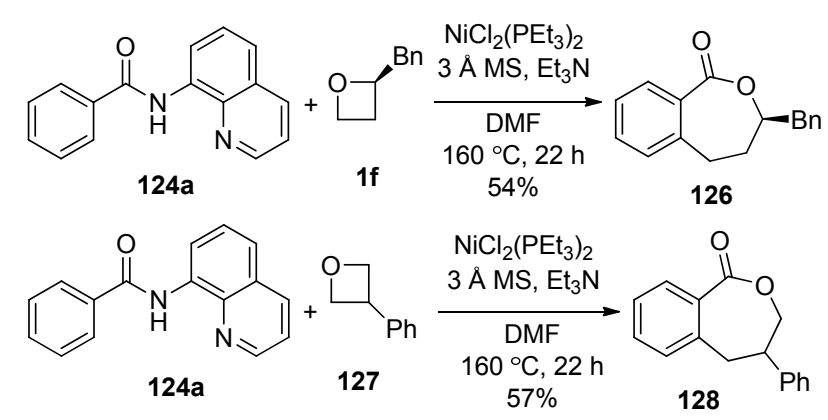
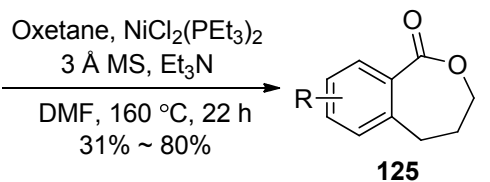

125
图式 35 苯甲酰胺与氧杂环丁烷的扩环反应

Scheme 35 Ring expansion reaction of benzamides and oxetanes

\section{5 总结与展望}

氧杂环丁烷不仅是许多天然产物和药物分子中的 重要活性结构单元，同时也是有机合成的重要原料和中 间体. 经过多年的发展, 氧杂环丁烷的开环反应发展迅 速, 相对来说, 单纯的扩环反应相对较少, 但在近年来 得到了很好的发展. 通过氧杂环丁烷扩环反应制备所需 含氧普通杂环化合物到大环含氧化合物具有重要意义, 是一种制备冠醚类化合物的有效方法. 目前报道的氧杂 环丁烷的扩环反应, 立体化学不易控制, 副反应较多, 产率大多数偏低, 反应种类也有限. 因此, 今后需要进
一步探索和拓展氧杂环丁烷新的扩环反应，并拓宽其应 用范围，实现操作简单、成本低、产率高及选择性好的 氧杂环丁烷的扩环反应，进一步提高氧杂环丁烷类化合 物在有机化学、药物化学和材料化学中的应用.

\section{References}

[1] Burkhard, J. A., Wuitschik, G.; Rogers-Evans, M.; Muller, K.; Carreira, E. M. Angew. Chem., Int. Ed. 2010, 49, 9052.

[2] Bull, J. A.; Croft, R. A.; Davis, O. A.; Doran, R.; Morgan, K. F. Chem. Rev. 2016, 116, 12150.

[3] Ma, L. G.; Xu, J. X. Prog. Chem 2004, 16, 220 (in Chinese) (马琳鸽, 许家喜, 化学进展, 2004, 16, 220).

[4] Zhou, C.; Xu, J. X. Prog. Chem 2011, 23, 174 (in Chinese) (周婵, 许家喜, 化学进展, 2011, 23, 174).

[5] Zhou, C.; Xu, J. X. Prog. Chem 2012, 24, 338 (in Chinese) (周婵, 许家喜, 化学进展, 2012, 24, 338).

[6] Xu, C.; Xu, J. X. J. Org. Chem. 2018, 83, 14733.

[7] Li, S. Q.; Shi, Y.; Li, P. F.; Xu, J. X. J. Org. Chem. 2019, 84, 4443.

[8] Chen, X. P.; Lin, C.; Du, H. G.; Xu, J. X. Adv. Synth. Catal. 2019, $361,1647$.

[9] Dong, J.; Du, H. G.; Xu, J. X. J. Org. Chem. 2019, 84, 10724.

[10] Shi, Y.; Li, S. Q.; Lu, Y.; Zhao, Z. Z.; Li, P. F.; Xu, J. X. Chem. Commun. 2020, 56, 2131.

[11] Chen, X. P.; Xu, J. X. Prog. Chem 2017, 29, 181 (in Chinese) (陈兴鹏, 许家喜, 化学进展, 2017, 29, 181).

[12] Li, S. Q.; Xu, J. X. Prog. Chem. 2016, 28, 1798 (in Chinese) (李思琦, 许家喜, 化学进展, 2016, 28, 1798).

[13] Xu, W.; Xu, J. X. Curr. Org. Synth. 2016, 13, 73.

[14] Xu, J. X. Top. Heterocycl. Chem. 2016, 41, 311.

[15] Malapit, C. A.; Howell, A. R. J. Org. Chem. 2015, 80, 8489.

[16] Mack, D. J.; Njardarson, J. T. ACS Catal. 2013, 3, 272.

[17] Nozaki, H.; Moriuti, S.; Takaya, H.; Noyori, R. Tetrahedron Lett. 1966, 7, 5239.

[18] Nozaki, H.; Takaya, H.; Moriuti, S.; Noyori, R. Tetrahedron 1968 , 24, 3655 .

[19] Ito, K.; Katsuki, T. Chem. Lett. 1994, 23, 1857.

[20] Ito, K.; Yoshitake, M.; Katsuki, T. Chem. Lett. 1995, 24, 1027.

[21] Katsuki, T.; Ito, K.; Yoshitake, M. Heterocycles 1996, 42, 305.

[22] Ito, K.; Yoshitake, M.; Katsuki, T. Tetrahedron 1996, 52, 3905.

[23] Ito, K.; Fukuda, T.; Katsuki, T. Synlett 1997, 387.

[24] Katsuki, T.; Ito, K.; Fukuda, T. Heterocycles 1997, 46, 401.

[25] Lo, M. M.; Fu, G. C. Tetrahedron 2001, 57, 2621.

[26] Mack, D. J.; Batory, L. A.; Njardarson, J. T. Org. Lett. 2012, 14, 378.

[27] Jana, S.; Yang, Z.; Pei, C.; Xu, X.; Koenigs, R. M. Chem. Sci. 2019, 10, 10129.

[28] Egger, L.; Guenee, L.; Burgi, T.; Lacour, J. Adv. Synth. Catal. 2017, 359, 2918.

[29] Rix, D.; Ballesteros-Garrido, R.; Zeghida, W.; Besnard, C.; Lacour, J. Angew. Chem., Int. Ed. 2011, 50, 7308.

[30] Kitamura, M.; Kisanuki, M.; Kanemura, K.; Okauchi, T. Org. Lett. 2014, 16, 1554.

[31] Harmon, R. E.; Stanley, F.; Gupta, S. K.; Johnson, J. J. Org. Chem. 1970, 35, 3444.

[32] Guarnieri-Ibanez, A.; Medina, F.; Besnard, C.; Kidd, S. L.; Spring, D. R.; Lacour, J. Chem. Sci. 2017, 8, 5713.

[33] Larksarp, C.; Alper, H. J. Org. Chem. 1999, 64, 4152.

[34] Hudrlik, P. F.; Wan, C. J. Org. Chem. 1975, 40, 2963.

[35] Posner, G. H.; Hatcher, M. A.; Maio, W. A. Org. Lett. 2005, 7, 4301.

[36] Pawar, S. K.; Vasu, D.; Liu, R. Adv. Synth. Catal. 2014, 356, 2411.

[37] Sahani, R. L.; Liu, R. Chem. Commun. 2016, 52, 7482.

[38] Wang, Y.; Yang, L.; Rong, Z.; Liu, T.; Liu, R.; Zhao, Z. Angew. Chem., Int. Ed. 2018, 57, 1596.

[39] Xu, H.; Khan, S.; Li, H.; Wu, X.; Zhang, Y. J. Org. Lett. 2019, 21, 214. 
[40] Punna, N.; Das, P.; Gouverneur, V.; Shibata, N. Org. Lett. 2018, 20 , 1526.

[41] Das, P.; Gondo, S.; Nagender, P.; Uno, H.; Tokunaga, E.; Shibata, N. Chem. Sci. 2018, 9, 3276

[42] Uno, H.; Imai, T.; Harada, K.; Shibata, N. ACS Catal. 2020, 10, 1454 .

[43] Guo, B.; Schwarzwalder, G.; Njardarson, J. T. Angew. Chem., Int Ed. 2012, 51, 5675.

[44] Gronnier, C.; Kramer, S.; Odabachian, Y.; Gagosz, F. J. Am. Chem. Soc. 2012, 134, 828

[45] Dong, J.; Xu, J. Org. Biomol. Chem. 2017, 15, 836.

[46] Baba, A.; Kashiwagi, H.; Matsuda, H. Tetrahedron Lett. 1985, 26, 1323.

[47] Baba, A.; Shabata, I.; Fujiwara, M.; Matsuda, H. Tetrahedron Lett. 1985, 26, 5167.

[48] Baba, A.; Kashiwagi, H.; Matsuda, H. Organometallics 1987, 6, 137.

[49] Shibata, I.; Imoto, T.; Baba, A.; Matsuda, H. J. Heterocycl. Chem. 1987, 24, 316

[50] Fujiwara, M.; Imoto, T.; Baba, A.; Matsuda, H. J. Org. Chem. 1988, $53,5975$.

[51] Darensbourg, D. J.; Ganguly, P.; Choi, W. Inorg. Chem. 2006, 45, 3831.

[52] Darensbourg, D. J.; Moncada, A. I.; Choi, W.; Reibenspies, J. H. J.
Am. Chem. Soc. 2008, 130, 6523 .

[53] Darensbourg, D. J.; Moncada, A. I. Macromolecules 2009, 42, 4063.

[54] Darensbourg, D. J.; Moncada, A. I. Macromolecules 2010, 43, 5996.

[55] Darensbourg, D. J.; Horn, A. Jr.; Moncada, A. I. Green Chem. 2010, $12,1376$.

[56] Whiteoak, C. J.; Martin, E.; Belmonte, M. M.; Benet-Buchholz, J.; Kleij, A. W. Adv. Synth. Catal. 2012, 354, 469.

[57] Whiteoak, C. J.; Kielland, N.; Laserna, V.; Escudero-Adan, E. C.; Martin, E.; Kleij, A. W. J. Am. Chem. Soc. 2013, 135, 1228.

[58] Rintjema, J.; Guo, W.; Martin, E.; Escudero-Adan, E. C.; Kleij, A. W. Chem.-Eur. J. 2015, 21, 10754.

[59] Buckley, B. R.; Patel, A. P.; Wijayantha, K. G. Eur. J. Org. Chem. 2015, 3, 474 .

[60] Chen, F.; Liu, N.; Dai, B. ACS Sustainable Chem. Eng. 2017, 5, 9065.

[61] Liu, N.; Xie, Y.; Wang, C.; Li, S.; Wei, D.; Li, M.; Dai, B. ACS Catal. 2018, 8, 9945.

[62] Butova, E. D.; Barabash, A. V.; Petrova, A. A.; Kleiner, C. M.; Schreiner, P. R.; Fokin, A. A. J. Org. Chem. 2010, 75, 6229.

[63] Xu, S.; Takamatsu, K.; Hirano, K.; Miura, M. Chem.-Eur. J. 2019, 25,9400 . 